\title{
Application of Road Transportation System to Generate Electricity via Road Humps in Lagos State, Nigeria
}

\author{
Adekunle A, Nwaigwe D.N, Nya Essang and Samuel P.O. \\ Nigerian Building and Road Research Institute (NBRRI) \\ Federal Ministry of Science and Technology \\ Nigeria
}

\begin{abstract}
Research has demonstrated that road transportation can be a source of electricity generation thereby creating jobs and improving the economic circumstances in the country. This paper attempts to illustrate how energy can be produced, stored and used, using road transport pressure from road humps. It also explains plainly, the working principle of the electromechanical device, its practical performance, and its benefits. There is a possibility of siphoning the energy and generating electric current thereby making the road hump as a power generation entity. This method is an effective way to produce electricity as the numbers of vehicles on the road are ever increasing. It can be effectively placed near traffic lights, at the entrance of parking lots and any other place where the traffic density is high. The generated power can be diverted to the national grid and increase power in megawatts.. The result from the device shows efficiency of $13.75 \%$ for a $7 \mathrm{~kg}$ load.
\end{abstract}

Key words: Road hump, Road transport, Electricity, Vehicle.

\section{INTRODUCTION}

A road hump is a synthetic crest into the exterior of the lane or road and it makes vehicular drivers drive at a low speed. It tends to serve as a technology that reduces the speed of vehicles within the city thereby improving safety (Anders, 2008). The need for power in this present age cannot be overemphasized. Energy in all facets of life goes a long way in determining the quality of any economy. In this paper, major concern is to store energy through road hump. The average number of vehicles on roads in the last decade has increased tremendously and still increasing. An electro-mechanical unit to store electrical energy for power generation is positioned beneath the road hump. A large amount of energy is wasted at the speed breakers on daily basis through heat and friction, anytime a vehicle goes on it. It is very possible to siphon this energy and consequently power generation unit. The generated power can as much as possible be used for street lights, traffic signals, etc.

This technology has been found by researchers to generate electricity to power up a household using a gadget that can move vehicles (Hindman, 2009).Hernandez exclaimed that electric energy production varies proportional to the flow of cars over a particular position (Paul, 2010).Nevertheless, in places where cars move in small numbers, a number of ramp steps were placed to multiply the force of every individual vehicle. The designer also added, the technology would be of immense advantage where there is a high number of vehicle movement.

Over the years, various researchers and scientist have developed systems in which the weight transferred through cars' wheels onto the road is used to generate electricity. These systems employ semiconductor materials which are very effective, but they're also too dear for use in many countries of the world (Sharma, 2003).Researchers in the Philippines say that as vehicles go by on roads, they use piezoelectric crystals that produce a small amount of energy which can go all the way and huge amounts of power can be produced which could eventually be sent back to the national grid (Alok et al, 2013).. 


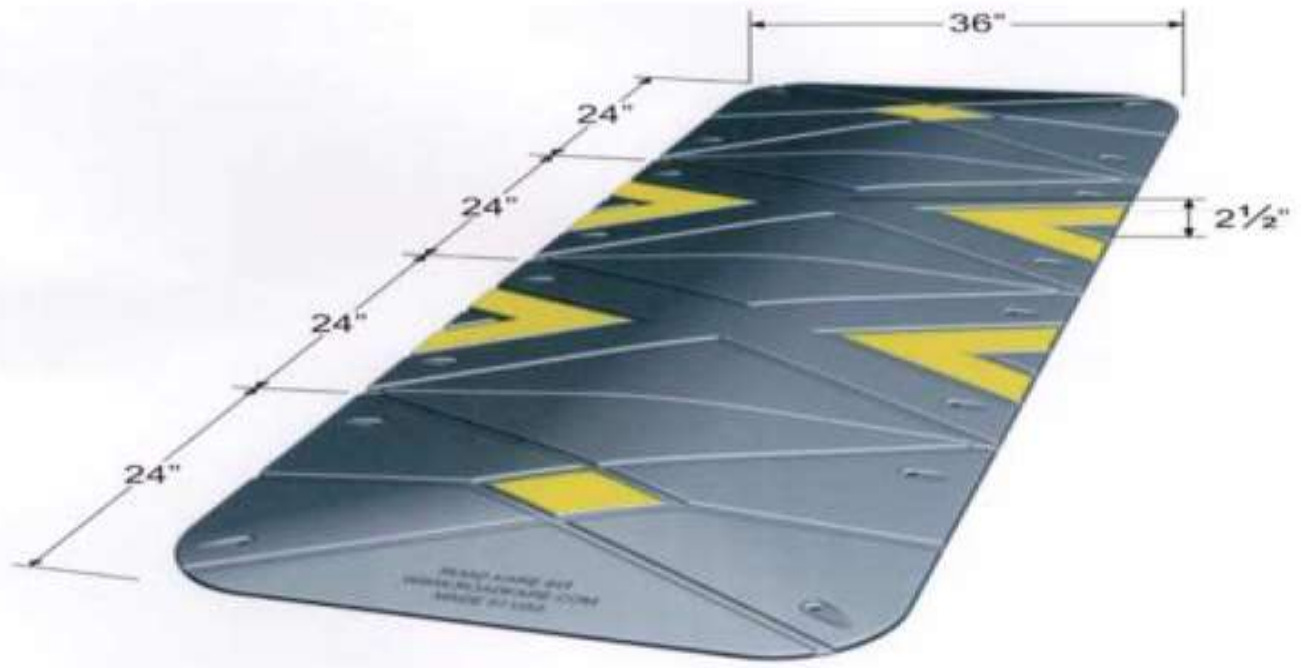

Plate 1:A typical road hump and its dimensions

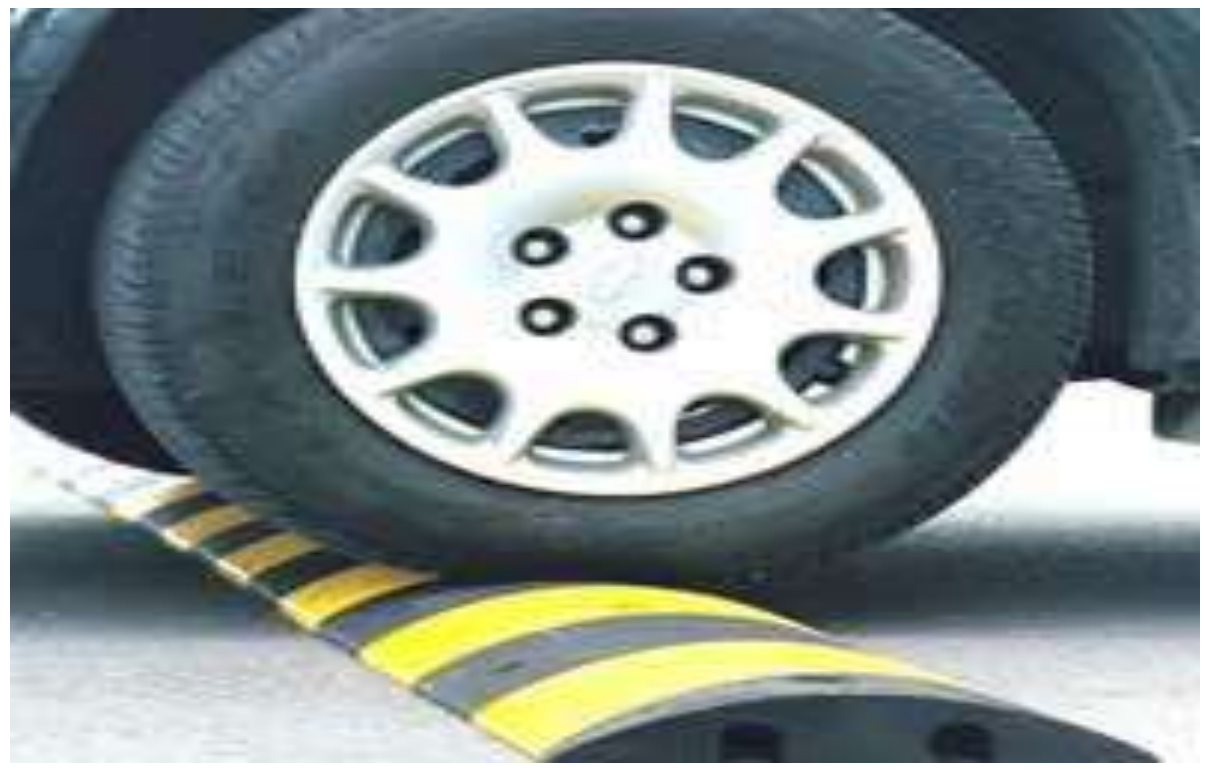

Plate 2: A photograph showing a car stepping on a road hump

\subsection{Aim And Objectives}

The aim of this paper is to show the application of road transportation to generate electricity through road humps while the objectives are:

$>$ To provide the project electrical circuit diagram

$>$ To provide a model diagram for the device

$>$ To determine the input power, output power and the efficiency of the device.

\section{METHODOLOGY}

\subsection{Project Electrical Circuit Diagram}

As soon as vehicles pass through the road humps, they applied pressure on the lever and as result causing the gears to rotate thereby generating electric current. Once electricity is produced in the direct current (DC) generator, current passes through a diode rectifier which allows current in only one direction. The switch allows the current to flow when closed while the resistor helps to impede the amount of current flow in the circuit. When power is needed during the night time, selector switch comes on and rechargeable battery supplies required power. 


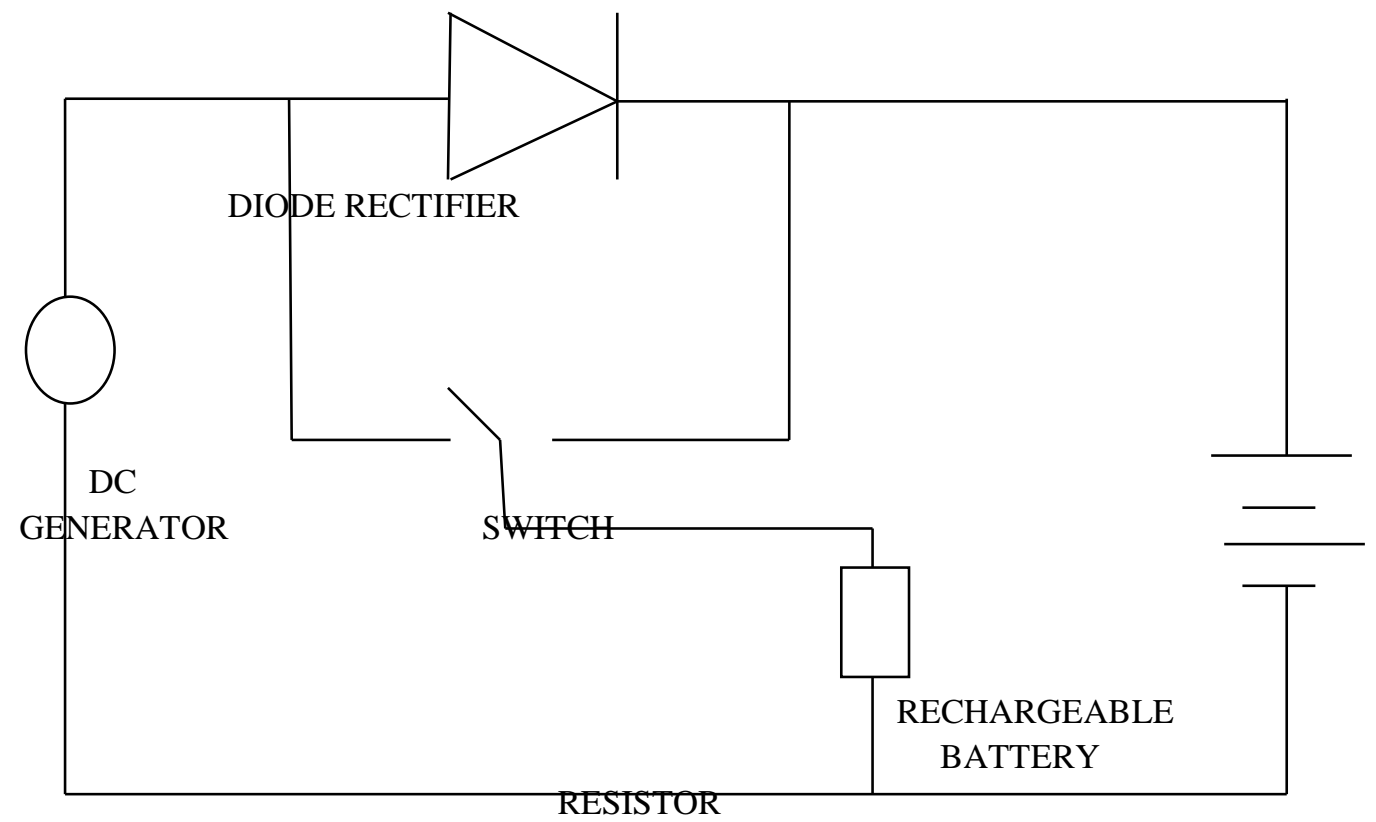

Fig. 2.1: Circuit Diagram of the System

\subsection{System Design And Arrangement}

Pressure is created on the lever as soon as a vehicle steps on the specially made road hump, this lever positioned under such humps makes the flywheel to rotate in a cycle thereby causing the DC generator to produce electrical energy. This electricity can in turn be stored by a rechargeable battery for other purposes. The produced or stored electricity is used for lighting bulb during night time on the road side, illuminating street lights, traffic signals etc. If $10 \mathrm{~kg}$ weight is applied on the pressure lever, the lever travels a distance of 0.172 meter $(\mathrm{m})$ and the total time taken to travel this distance is 0.83 second(s) and the RPM for one Stroke is 1014. By one stroke sprocket gear moves three teeth from its new position.

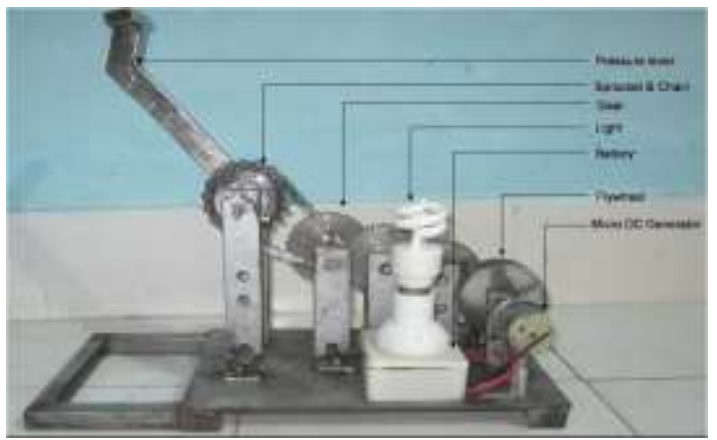

Fig 2.2: MODEL DIAGRAM (Ankit Gupta et al, 2012)

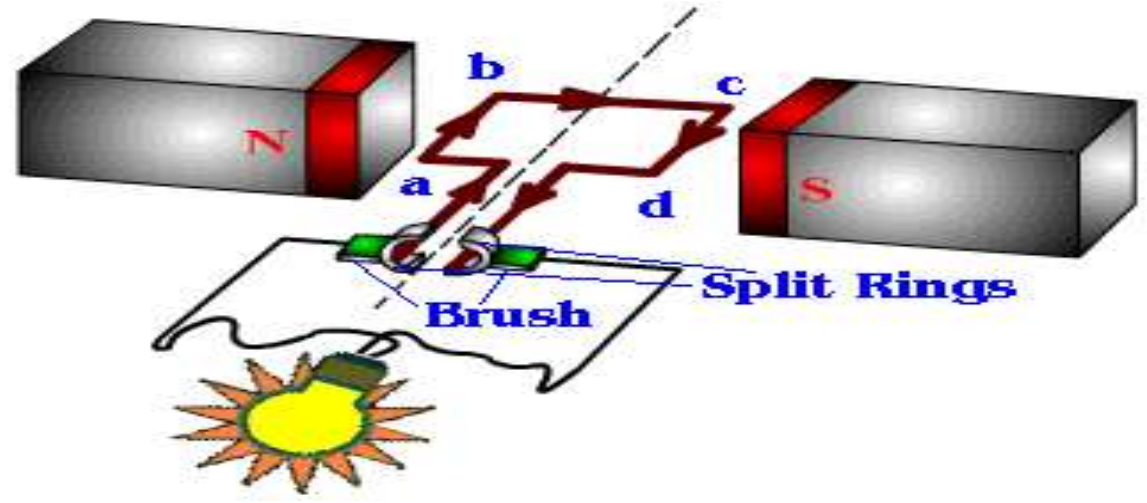

Fig 2.3: DC GENERATOR SCHEMATIC DIAGRAM (Paul Smith, 2010) 
The system in figure 2 is erected underground below road hump on busy roads as approved by builders, urban planners and road constructors. When pressure lever is pushed due to weights of cars on the road, the flywheel will rotate by sprocket gear mechanism, it will be forced to rotate the DC generator because DC generator and flywheel are in same shaft. DC generator will produce electricity by the rotation of armature coil and generated electricity will be stored in a rechargeable battery and consequently used later for lighting purposes.

\subsection{GENERATOR PROTOTYPE}

A dc generator is an electrical machine which converts mechanical energy into direct current electricity. This is based on principle of dynamically induced EMF. The parts of the machine are stator and rotor. The constructional parts are yoke, poles, pole shoe, field winding, armature core, armature winding and commutator and brushes.

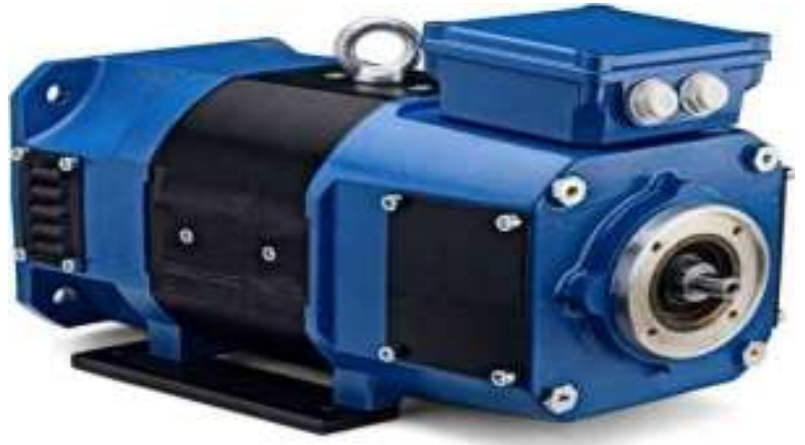

Fig2.4: DC GENERATOR PROTOTYPE

\subsection{FLYWHEEL}

A flywheel is a mechanical device designed to store rotational energy. It resists canes in rotational speeds by their moment of inertia. Te amount of energy stored in a flywheel is proportional to the square of its rotational speed. It's made of steel and rotate on conventional bearings and limited to maximum revolution rate, RPM. They are often used to provide continuous power output in systems were the energy source is not continuous.

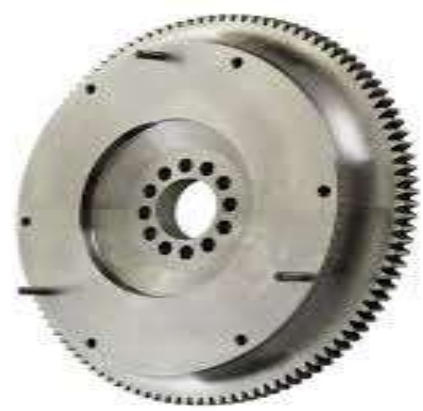

Fig 2.5: FLYWHEEL

\subsection{SPROCKET}

A sprocket is a profiled wheel with teeth that mesh with chain. The name sprocket applies to any wheel upon wich radial projections engage a chain passing over it. It is distinguished from a gear in that sprockets are never meshed togeter directly.

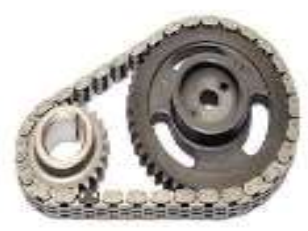

Fig 2.6: CHAIN AND SPROCKET 
International Journal of Advances in Scientific Research and Engineering (ijasre), Vol 5 (4), April-2019

\subsection{RESULTS AND DISCUSSION}

The sprocket ratio is a function of the relative sizes of the driving and driven sprockets. This is simply the number of teeth on the driving sprocket divided by the number of teeth on the driven sprocket

$$
\begin{array}{ll}
=\frac{T 2}{T 1} \text {, where } \mathrm{T} \text { is number of teeth } & \text { Eqn. (1) } \\
=\frac{N i}{N j}=\frac{T j}{T i} & \text { Eqn. (2) } \\
\mathrm{C}=\frac{P}{8}\left(2 \mathrm{~L}-\mathrm{N}-\mathrm{n}+\sqrt{(2 L-N-n)^{2}}-0.810(N-n)^{2}\right. & \text { Eqn. (3) }
\end{array}
$$

Where:

$\mathrm{C}=$ center to center distance in inches

$\mathrm{L}=$ Chain length in pitches

$\mathrm{P}=$ pitch of chain

$\mathrm{N}=$ number of teeth in large sprocket

$\mathrm{n}=$ number of teeth in small sprocket

The flywheel, gear 08 \& DC generator shaft are connected on the same shaft

Table 3.1: Magnitude of center distance levels

\begin{tabular}{|c|c|c|c|c|}
\hline Chain Length(M) & $\begin{array}{c}\text { Number of Teeth in } \\
\text { Large Sprocket }\end{array}$ & $\begin{array}{c}\text { Number of Teeth in } \\
\text { Small Sprocket }\end{array}$ & Pitch of Chain & $\begin{array}{c}\text { Center to } \\
\text { Center Distance } \\
\text { (Inches) }\end{array}$ \\
\hline 30 & 25 & 10 & 18 & 103.5937 \\
\hline 45 & 35 & 20 & 27 & 227.1093 \\
\hline 55 & 45 & 30 & 37 & 311.2238 \\
\hline 65 & 55 & 40 & 45 & 378.5155 \\
\hline 75 & 65 & 50 & 52 & 437.3957 \\
\hline 85 & 75 & 60 & 61 & 513.0988 \\
\hline 95 & 85 & 70 & 71 & 597.2133 \\
\hline 120 & 95 & 80 & 87 & 1398.336 \\
\hline 130 & 105 & 90 & 92 & 1478.7 \\
\hline 140 & 115 & 100 & 134 & 2153.759 \\
\hline
\end{tabular}

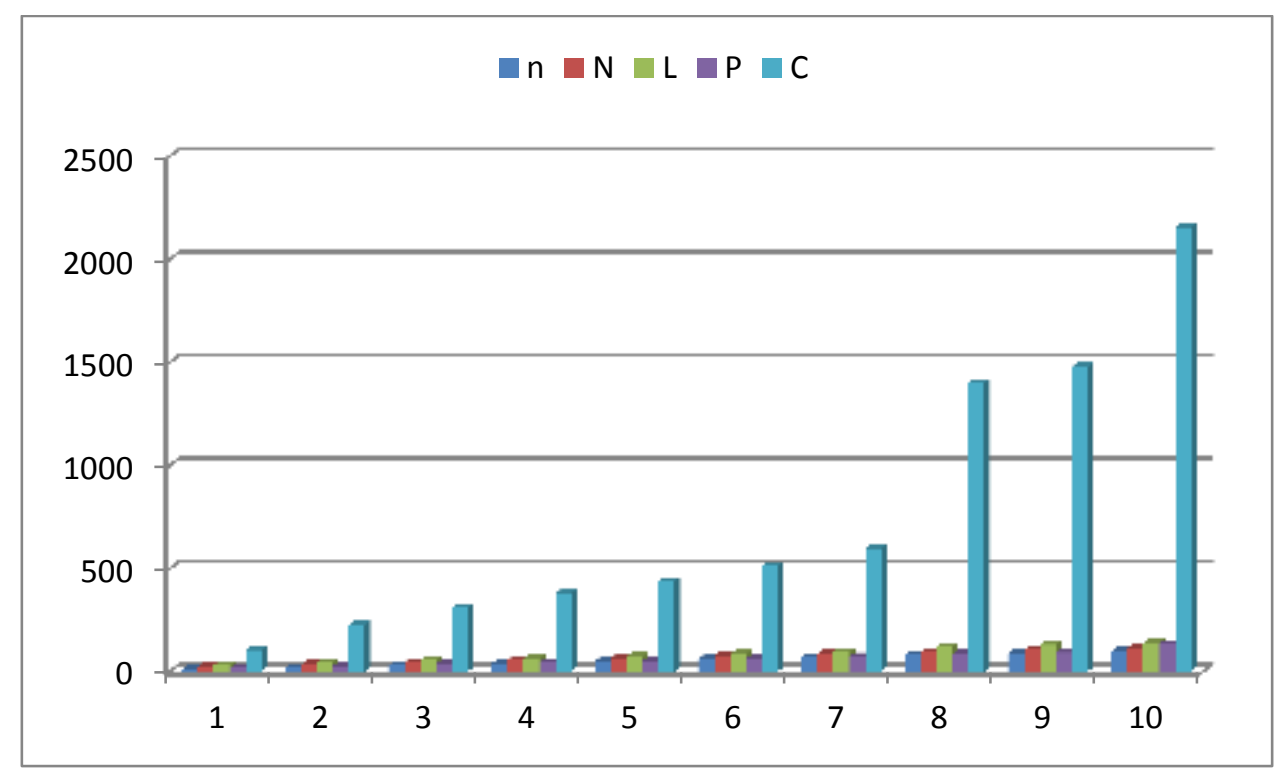

Figure 3.1: Center to center distance against chain parameters

Input Power using a car load of $7 \mathrm{~kg}$ 
International Journal of Advances in Scientific Research and Engineering (ijasre), Vol 5 (4), April-2019

Work done,

$$
\begin{aligned}
& \mathrm{W}=\text { applied force } * \text { distance travel } \\
& \mathrm{W}=20 \times 9.81 \times 0.152=29.82 \text { Joule }
\end{aligned}
$$

Input Power, $\mathrm{P}=$ Total work done $/$ total time taken to do the work

$$
\mathrm{P}=29.82 / 0.717=41.6 \mathrm{Watt}(\mathrm{w})
$$

Output Power of the device

Output power, $\mathrm{Po}=$ Voltage $\mathrm{x}$ Current

$$
\mathrm{Po}=\mathrm{V} * \mathrm{I}=4.0 \times 0.5=2 \mathrm{Watt}(\mathrm{w})
$$

Eqn. (5)

\section{Efficiency Calculation}

Efficiency $=$ (Output Power/Input Power) X $100 \%$

Eqn. (6)

Efficiency $=(2 / 14.55)$ X $100 \%=\mathbf{1 6 . 4 5} \%$

Table 3.2: Loads against their corresponding powers and efficiencies

\begin{tabular}{|l|l|l|l|}
\hline LOAD(Kg) & INPUT POWER(W) & OUTPUT POWER(W) & EFFICIENCY (\%) \\
\hline 7 & 14.55 & 2.00 & 13.75 \\
\hline 20 & 18.75 & 3.08 & 16.45 \\
\hline 38 & 22.85 & 4.72 & 20.65 \\
\hline 54 & 26.45 & 6.65 & 25.15 \\
\hline 76 & $45 . .65$ & 22.03 & 48.25 \\
\hline 89 & 55.95 & 28.62 & 51.15 \\
\hline 123 & 76.55 & 51.57 & 67.35 \\
\hline 150 & 89.65 & 66.57 & 74.25 \\
\hline 190 & 105.56 & 83.87 & 79.45 \\
\hline 230 & 135.75 & 112.88 & 83.15 \\
\hline 270 & 185.95 & 160.75 & 86.45 \\
\hline
\end{tabular}

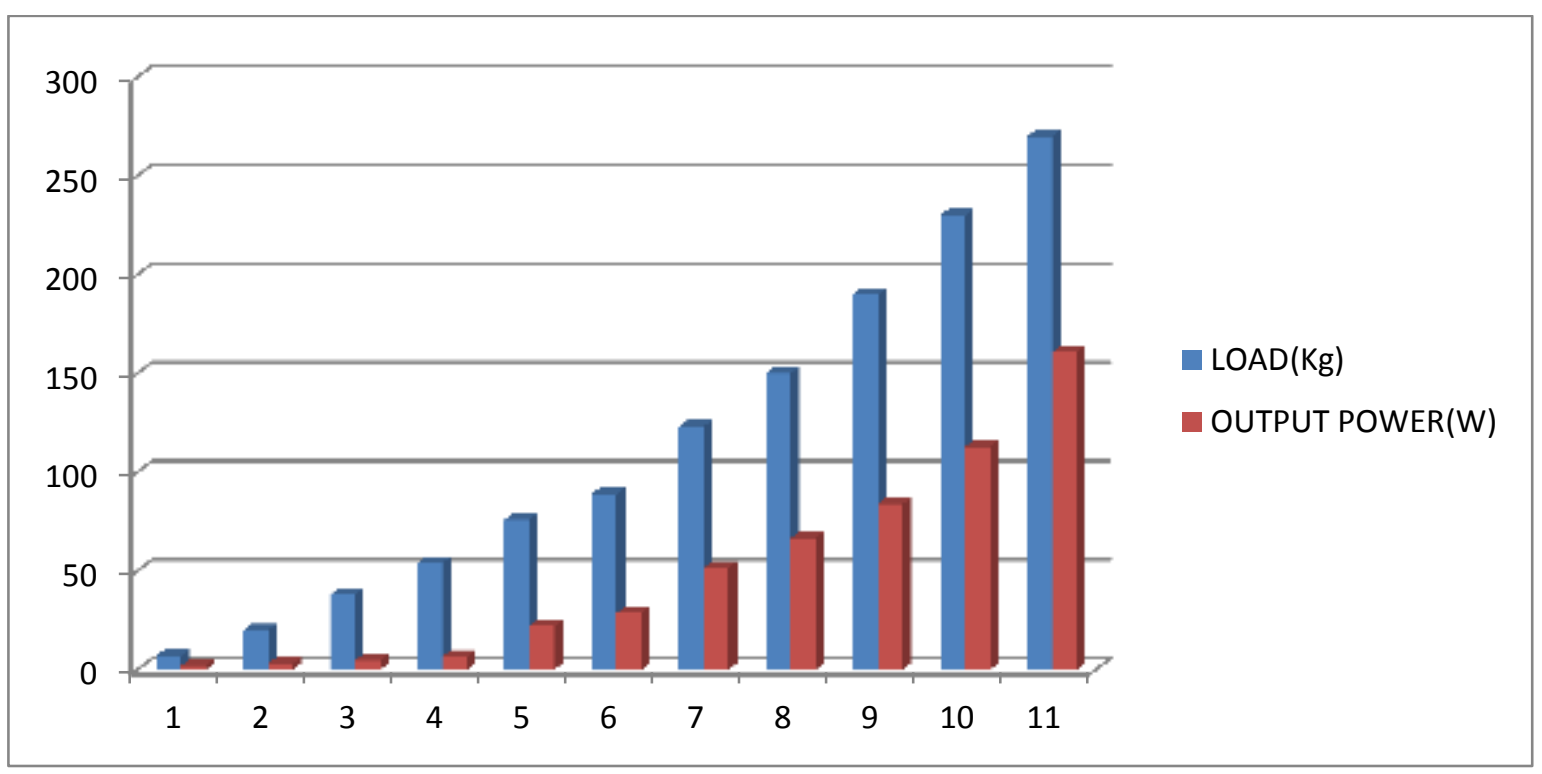

Figure 3.2: Car load against output power 


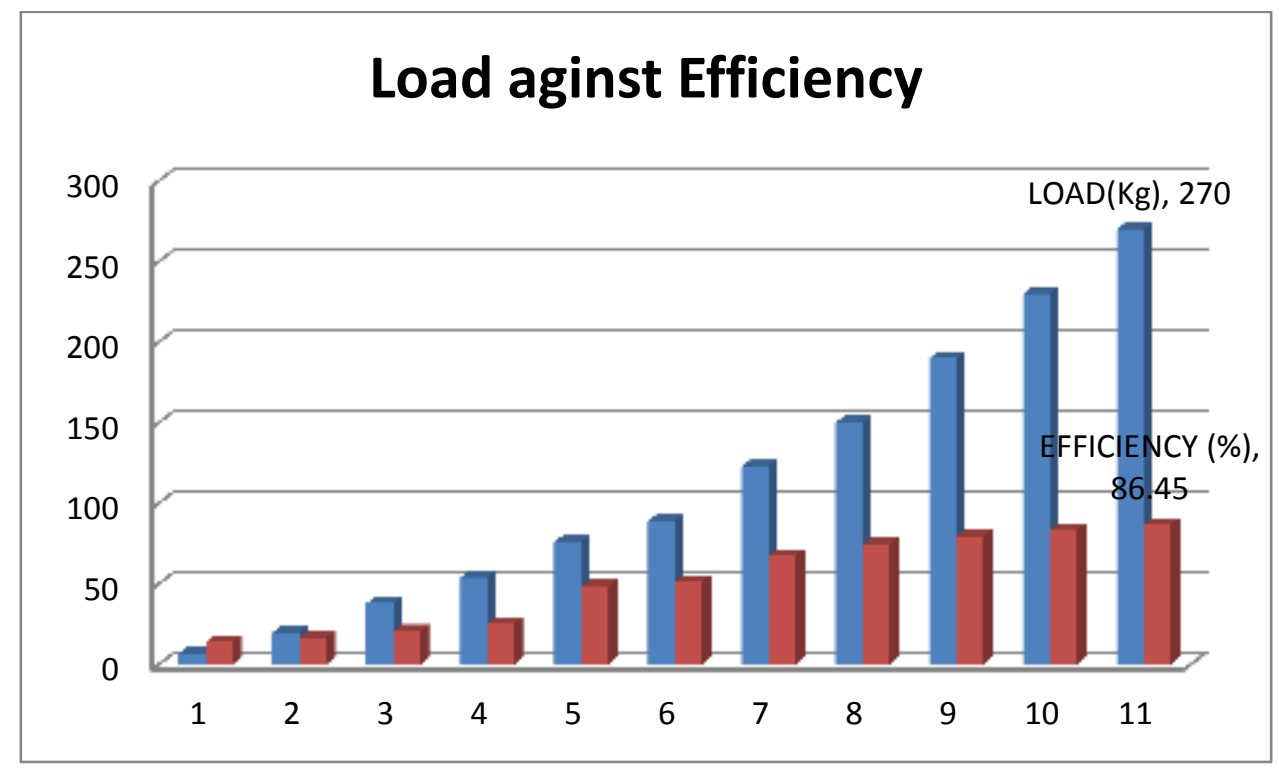

Figure 3.3: Car load against Efficiency

Table 3.1, figure 3.1 and 3.2 show that surely pressure from vehicles passing over speed breakers can generate electric power and can be converted to the national grid As the load increases, the output power increases thereby increasing the efficiency too. This suggests that with little or no pressure on such speed breakers, it will be difficult to produce electricity (Sharma, 2003). It can also be deduced from table 1 that the higher the number of cars that crosses the breakers, the higher the amount of electric power produced.

\subsection{CONCLUSION}

The entire paper deals with generating electricity using road transportation technology. An electromechanical device positioned under such road humps thereby generating electric current.

The wasted mechanical energy can therefore be converted into electrical power. As soon as pressure lever is pushed due to weights of cars on the road, the flywheel will revolve by sprocket gear mechanism, it will be forced to rotate the DC generator because DC generator and flywheel are in same shaft. DC generator will produce electricity by the rotation of armature coil and generated electricity will be stored in a rechargeable battery and consequently used later for lighting purposes In future, if the flywheel speed control device and voltage protection devices are added with large generation process, it would be a replica all over the world. With adequate modification of this system, the efficiency of the whole system can be amplified by increasing the capacity of the generator and applying more weight.

\section{REFERENCES}

1. Anders Brandt, "Bus Drivers Exposure to Mechanical Shocks Due To Speed Humps". Society for Experimental Mechanics, IMAC 25th Conference and Exposition on Structural Dynamics 2008.

2. Ankit Gupta, KuldeepChaudhary\& B.N Agrawal, An Experimental study of Generation of Electricity using Speed Breaker, International Journal of Mechanical Engineering (IJME ), 1(1), 2012, 35-40

3. Aswathaman. V, Priyadharshini.M, Every Speed Breaker Is Now A Source of Power; International Conference on Biology, Environment and Chemistry (IPCBEE), 1, 2011, 234 - 236.

4. E.G. Alok, K. S., Deepak, S., Madhawendra, K. and Vijay, P. (2013).Generation of Electricity through Speed Breaker Mechanism. International Journal of Innovations in Engineering and Technology (IJIET), Vol. 2(2), Pp 20-24.

5. Hindman Sanchez, "Smart Stopping Speeders in the Community, Smart Speed Humps reward safe drivers". International conference on road traffic reduction, Australia, 2009

6. Paul Smith, "Production of electricity by the method of road power generation", IJAEEE, 2010.

7. Shakun Asthana, "produce electricity by the use of speed breakers," Journal of Engineering Research and Studies, Vol.2, No.1 April-Jun 2011. 
8. Sharma Park, "Non-conventional power plants", Public Printing Service, New Delhi, 2003.

9. Shirley Jack. "Smart road hump will smooth the way for safe drivers", Providence Journal, November 11, 2005. 